\title{
Teoría y sujetos sociales. Algunas consideraciones acerca de los estudios sobre el campesinado en Argentina
}

\author{
Marcelo Germán Posada
}

Universidad Nacional de Luján. Facultad Latinoamericana de Ciencias Sociales (FLACSO). Departamento de Ciencias Sociales

Argentina

\section{Resumen}

Aunque existen muchos estudios sobre el agro pampeano desde la economía y la sociología rural, la figura del campesino ha sido menos analizada desde la perspectiva de la sociología.

Palabras clave: Pampa argentina, sociología rural, campesino, sociología del campesinado.

\section{Abstract. Theory and social subjects. About the studies on the Argentinian peasants}

Although several studies on the Argentinian agriculture and land exploitation exist from the economists' and rural sociologists' point of view, peasants have been less analysed from the sociological perspective.

Key words: Argentinian pampa, rural sociology, peasant, sociology of peasantry.

\section{Introducción}

La dirección que tomó el desarrollo económico argentino, asentada sobre la expansión de la producción agropecuaria pampeana, marcó en gran medida las preocupaciones académicas acerca del carácter de la misma. A lo largo de las décadas se multiplicaron los estudios económicos, econométricos, sociales e históricos que intentaron desentrañar la matriz de origen de dicha evolución, como así también el desarrollo futuro del sector y de la región en general. Los análisis políticos tampoco estuvieron ausentes de estas preocupaciones; son muchos los textos que versan sobre la estructura social pampeana, sobre la forma de producción predominante en la región, acerca de la dirección que adoptará la actividad agropecuaria, etc.

La notable preponderancia pampeana hizo perder de vista al agro del resto del país. No queremos decir con esto que no existan investigaciones, ensayos y discusiones sobre la situación agraria en el interior de la Argentina. Lo que intentamos expresar es que el papel desempeñado por la región pampeana impidió que se centrara la discusión en importantes aspectos del desarrollo agrario extrapampeano. Así, no se asistió nunca a un debate sobre la asigna- 
ción de recursos en las explotaciones agrarias, por ejemplo para la región noroeste, como el que ocurrió entre fines de los sesenta y mediados de los setenta para la pampeana.

Podemos decir que desde fines de la década de 1960 es cuando comienzan a sistematizarse estudios que se centran en el agro extrapampeano. Los trabajos realizados por el Grupo de Sociología Rural, del Servicio de Economía y Sociología Rural (dependiente de la Secretaría de Agricultura, Ganadería y Pesca de la Nación), los efectuados por técnicos del Consejo Federal de Inversiones, los estudios llevados desde el Centro de Investigaciones en Ciencias Sociales (CICSO) son sólo algunos ejemplos de los nuevos bríos que alcanzó este campo de estudio.

Si bien los estudios sociales y económicos siguen teniendo por objeto en gran número de veces al agro pampeano, ya se dispone de un corpus de investigaciones y reflexiones sobre la economía y la sociedad rural extrapampeana. Del mismo, en este breve estudio queremos analizar a aquellos que tratan sobre un sujeto que en reiteradas ocasiones es presentado como el actor fundamental de la actividad agropecuaria analizada; nos referimos a la figura del campesino. Para esto nos referiremos sucintamente a la teoría del campesinado, a su aplicación a nuestro país y, finalmente, se analizarán algunos estudios seleccionados.

A diferencia del resto de América Latina, donde la discusión campesina es de larga data, y donde hubo un desarrollo teórico considerable, en Argentina tal temática carece de una prolongada tradición. No vamos a encontrar reflexiones ni discusiones del tenor de las llevadas a cabo por los campesinistas y descampesinistas mexicanos, ni un volumen de estudios de caso, como los efectuados en Ecuador o Perú. Por tal motivo, debemos partir de un somero repaso de las posturas teóricas sobre los campesinos en general, con el objetivo de ubicar al lector en torno a los sujetos de análisis.

[...] la familia campesina, una familia que no contrata fuerza de trabajo exterior, que tiene una cierta extensión de tierra disponible, sus propios medios de producción y que a veces se ve obligada a emplear parte de su fuerza de trabajo en oficios rurales no agrícolas ${ }^{1}$.

Tal es la unidad de análisis que selecciona Alexander Chayanov para su estudio sobre el campesinado ruso. En este texto abrevarán buena parte de los analistas del campesino latinoamericano. De él se deriva la noción de economía campesina, como una forma especial de organización de la producción. La economía campesina encerraría al sector agropecuario donde el proceso productivo se desarrolle en unidades del tipo familiar, teniendo por objetivo asegurar, de ciclo en ciclo, la reproducción de sus condiciones de vida y de trabajo, es

1. A. Chayanov (1985: 44). 
decir, la reproducción de los productores y de la misma unidad de producción. En otras palabras, la explotación debe generar los medios necesarios para asegurar el sostenimiento biológico de los integrantes de la familia y la satisfacción de las otras necesidades, cultural e históricamente determinadas, como así también debe proveer de los medios para reponer los bienes consumidos en la realización del ciclo productivo. Incluso, como sostiene Wolf, será menester que genere además un fondo de ceremonial y otro de renta ${ }^{2}$.

El manejo productivo campesino, persiguiendo los objetivos descritos, se basa en "[...] una racionalidad propia y distinta de la que caracteriza a la agricultura empresarial $»^{3}$. Tal como lo expuso Chayanov, la actividad económica de la familia campesina se rige por el equilibrio existente entre el consumo de los miembros de la misma y la autoexplotación del trabajo. El agrónomo ruso elabora la ecuación de trabajo y consumo, diseñando una matriz donde se combinan el tamaño de la familia y la relación entre miembros que realizan actividades (trabajadores) y miembros que no lo hacen (consumidores). El resultado de ese cruce va a señalar el grado de "penoso esfuerzo" que requiere la combinación entre el trabajo, la tierra y los instrumentos de trabajo. Cuando los requerimientos de los consumidores sean mayores, más elevado será el grado de autoexplotación del trabajo familiar, mientras que cuando la presión derivada de una relación desfavorable (menos consumidores por cada trabajador) disminuya, la autoexplotación evolucionará en concordancia ${ }^{4}$.

En el modelo teórico de Chayanov la única categoría económica visible es la remuneración del trabajo, equivalente al ingreso anual, disponible para la familia después de deducir los gastos. No hay salarios imputables al trabajo familiar, ni ganancia (que no se busca, dado que el nivel de actividad se regula por la satisfacción de las necesidades familiares), ni renta (en el sentido capitalista). El beneficio de la explotación se obtiene mediante el balance trabajo-consumo, establecido por el equilibrio «económico básico» entre las fatigas del trabajo y la satisfacción de necesidades. El producto bruto de la unidad se constituye mediante la sumatoria de todos los ingresos anuales de la misma, tanto agrícolas como extraagrícolas. Al descontarse los gastos de explotación y renovación del capital, se obtiene el producto neto. Éste será reconocido como satisfactorio o no por la evaluación subjetiva de las fatigas propias del trabajo que realiza la familia campesina.

Como se observa, en la unidad económica campesina de Chayanov, sí existe la categoría "capital», pero con leyes diferentes a las que lo rigen en una uni-

2. E. Wolf (1970).

3. CEPAL (1982: 62).

4. «La producción del trabajador en la explotación doméstica se detendrá en este punto de natural equilibrio porque cualquier otro aumento en el desgaste de fuerza de trabajo resultará subjetivamente desventajoso. Cualquier unidad doméstica de explotación agraria tiene así un límite natural para su producción, el cual está determinado por las proporciones entre la intensidad del trabajo anual de la familia y el grado de satisfacción de sus necesidades" (A. Chayanov, 1985: 85). 
dad capitalista. Su incremento, formación y renovación están sujetos al equilibrio básico de la unidad (intensidad de la fuerza de trabajo, satisfacción de las necesidades).

Hasta aquí los lineamientos más esquemáticos de los aportes teóricos de Alexander Chayanov ${ }^{5}$. Ahora, de realizarse ese análisis, difícilmente pueda hallarse el tipo ideal de unidad campesina descrita por el agrónomo ruso. Como sostiene Murmis, la unidad de producción fundada en la combinacion de tierra y trabajo familiar, "la unidad campesina por excelencia» no es más que un punto de referencia ${ }^{6}$. Por otro lado, como marca el mismo Murmis, el término campesino, ni su abarcante: pequeino productor, son conceptos teóricos y por ende son debatibles, aunque es claramente visible que son categorías dinámicas, en permanente evolución ascendente o descendente, alejadas de la estática vision chayanoviana.

Como se utilizó esta categoría analíica en los estudios sobre el agro argentino es lo que trataremos de describir en la sección siguiente.

En primer lugar veamos qué tipo de conceptualización se realizó del término campesino. Sabemos que el mismo se utiliza tanto para designar a un tipo social agrario como a una forma de organización económica - distinta de la capitalista-, pero también tiene implicancias culturales y religiosas. La carga teórica del término campesino es muy fuerte; remite a una sociedad global con fuerte peso de rasgos campesinos, donde

[...] la poblacion rural debe ser mayoritaria, el desarrollo capitalista débil y, por lo tanto, el sector industrial es incipiente y no está concentrado, una parte importante del trabajo productivo rural se dedica al ciclo de subsistencia, una gran proporción de los insumos productivos del campo se producen artesanalmente, el desarrollo de los mercados locales y regionales presenta características de dispersión de la oferta y de la demanda y el crédito es escaso ${ }^{7}$.

Por su parte, G. Foladori señala que el concepto campesino encierra un triple aspecto: un ámbito espacial: lo rural; un proceso en la división social del trabajo: lo agropecuario; un aglutinador demográfico: pequeńas comunidades ${ }^{8}$. Como podemos apreciar, estas condiciones no son las predominantes en Argentina: hallamos un proceso de industrialización de larga data, iniciado en

5. La influencia de Chayanov es señalada por $E$. Archetti: "El interés en la teoría de Chayanov, que puede explicarse no sólo en base a una ideología marginalista existente, sino también por la falta de una teoría consistente acerca de la economía campesina, puede ser justificado a través de un cuidadoso examen de sus hipótesis centrales" (1981a: 41).

6. M. Murmis (1992: 82).

7. E. Archetti (1981b: 207).

8. G. Foladori (1981). 
buena medida antes de comenzar la etapa sustitutiva, y que se reafirmó luego; el mercado adquiere una dimensión nacional desde que se organiza institucionalmente al país, y aun desde antes; la importancia de la producción de subsistencia es sumamente relativa, al tiempo que gran parte de los insumos agrícolas requeridos se adquieren en aquel mercado, que es donde se coloca lo obtenido en la explotación, comprándose también en él lo necesario para la vida diaria. Lejos está Argentina de presentar rasgos similares a los del agro peruano, ecuatoriano o boliviano, sin esa masa poblacional campesina, sin su tradición atávica de larga data, sin el componente indígena que prima en esos, y en otros países; vemos sumamente dificultoso el uso de este término referido a la realidad social agraria argentina. Hablar de campesinos sin especificación alguna, utilizándolo como un término genérico, abstrayéndolo del marco temporal histórico y social, no contribuye en nada a la explicación de la realidad social rural del país. En este marco es donde aparece como relevante el distingo que realiza Archetti sobre los usos del término en cuestión; sostiene que puede aplicarse en forma circunscripta a un tipo de productor agrario, que utiliza tecnología sencilla y fuerza de trabajo familiar; también es factible de aplicar para designar un modo de producción determinado, donde los campesinos son propietarios de la tierra, la poblacion rural será mayoritaria y el sector capitalista de la sociedad, débil. Por último, el término campesino fungiría como un término descriptivo para referirse a productores que organizan su unidad en torno a la mano de obra familiar?

En los estudios que se recopilan en esta revisión se observará que raramente se toma en un sentido amplio lo campesino, limitándoselo para identificar a ciertos sujetos sociales, por lo general asignándoseles ser portadores de una racionalidad diferenciada. Pero esta utilización implica un abandono de la tradición teórica, entendida no como una cristalización dogmática, sino como un campo común de entendimiento intelectual. Si llamo $A$ a un sujeto o una situación definida por $B$ y por $C$, qué sentido tiene seguir llamando $A$ a otro sujeto o situación, esta vez definida por $D$ y $E$ ?

Nos parece mucho más fructífero, y metodológicamente adecuado, emplear en los análisis la categoría de "pequeños productores". Como indicamos, tampoco es un concepto teórico, pero su uso nos evita cargar con lo que acarrea "lo campesino". Su delimitación incluye a todos aquellos sujetos que manejan unidades ubicadas entre estos dos extremos: un piso señalado por aquellas unidades productivas cuya significación es sumamente limitada, o nula, por ser muy pequeñas o semiproletarias; y un techo indicado algo más ambiguamente, que en Murmis es el nivel que evita basar a la unidad en la renta de la tierra, y que en Piñeiro y Llovet es la capacidad de comprar trabajo asalariado y comenzar a acumular ${ }^{10}$. Dentro de este espectro, los pequeños productores realizarán una amplia gama combinatoria de trabajo familiar y tierra; siendo estos dos factores productivos los ejes que se toman para delinear las numero-

9. E. Archetti (1981a: 31).

10. M. Murmis (1992: 80-81); M. Piñeiro e I. Llovet (1986a: 27). 
sas definiciones de campesinos, tanto en forma genérica como en el caso particular de nuestro pais ${ }^{11}$.

Por otro lado, seguir insistiendo en la utilización del término campesino, reduciéndolo a su significado económico, apareja una serie de peligros metodológicos y de análisis que distorsionan !a realidad estudiada. Orlando Plaza enumeró algunos de estos problemas:

1. Centrándose en el análisis micro de la unidad productiva, resaltando su autonomía, se puede caer en la ahistoricidad de la noción campesino, perdiendo todo contenido de relaciones sociales.

2. El sesgo economicista en que se suele incurrir impide analizar todos los aspectos que intervienen en su funcionamiento.

3. En cierto punto del análisis se puede acceder a un nuevo tipo de dualismo, donde dos sectores sociales conviven en un mismo país sin mayor vinculación entre sí.

4. Aun de optarse como elemento analítico la noción de economía campesina, al tratar de aislar sus componentes en el proceso productivo, se cae en el olvido de las propias relaciones sociales de esta economía, ignorándose los procesos y las instancias en que se inserta esa noción ${ }^{12}$.

\section{III}

Realizadas las anteriores consideraciones, pasemos a describir cómo se estudió al conjunto de los pequeños productores, y que los autores que tomaremos identifican con los campesinos.

Mabel Manzanal utiliza indistintamente "campesino" y "minifundista", aunque aceptando que la carga teórica del primero es mayor. Su definicion del campesino argentino — distinguiéndolo del latinoamericano- es:

Identificamos como campesinos a los productores agropecuarios que utilizando predominantemente la mano de obra familiar se distinguen de otros productores familiares por la ausencia de acumulación sistemática de capital, a causa de restricciones estructurales que lo impiden. En este contexto, el campesino asume una conducta que lo lleva a maximizar su ingreso global, para alcanzar la subsistencia del grupo familiar que vive en la explotación. La permanencia de la produccion campesina en el círculo vicioso de la pobreza es causada por restricciones sociales y económicas de carácter estructural ${ }^{13}$.

11. Citemos sólo un ejemplo de tal combinación de factores para elaborar una definición de campesinos: "[...] el campesino es un trabajador directo de la tierra que posee (ya sea en propiedad, arrendamiento o cualquiera otra forma de tenencia); que utiliza fuerza de trabajo familiar, a la que no remunera en dinero, y del total que produce guarda una parte para el autoconsumo y el resto lo destina al mercadom (S. Gómez, 1980: 6).

12. O. Plaza (1979: 20-23).

13. M. Manzanal (1990: 299). 
Francisco Delich, por su parte, veía a una sociedad rural argentina basada en campesinos y asalariados rurales, siendo los campesinos "una cuarta clase», ubicada entre la clase media rural y los asalariados ${ }^{14}$. Pedro Tsakoumagkos definió a las explotaciones campesinas como aquellas unidades domésticas de producción basadas en el trabajo familiar - no necesariamente exclusivo-y cuya dotación de medios de producción le impedirían superar el umbral de la acumulación ${ }^{15}$.

Archetti, en su estudio sobre la capitalización de los campesinos argentinos, recurre al bagaje teórico elaborado por Chayanov para analizar la zona norte de la provincia de Santa Fe; en el mismo se recurre indistintamente a los términos campesino, colono, farmer y productor familiar capitalizadon ${ }^{16}$.

R. Benencia señala en un trabajo de 1987 que en Argentina son asimilables los términos "campesinos" $\mathrm{y}$ "pequeños productores", pero en una reedición reciente del mismo ya no aparece tal acotacion, limitándose a utilizar al primero sin necesidad de referirlo al otro ${ }^{17}$. N. Giarraca y $S$. Aparicio, por su parte, derivan de la categoría analítica "campesinado" toda su elaboración tipológica sobre los productores de caña de azucar de la provincia de Tucumán, utilizando dos variables: el tipo de mano de obra empleada y el nivel de mecanización ${ }^{18}$.

Centrándose en el estudio de la provincia del Chaco, N. D'Alessio opta por definir como pequeña producción campesina al tipo de unidad productiva basada predominantemente en la fuerza de trabajo familiar ${ }^{19}$. Pero luego, analizando la generación de valor en estas producciones, precisa los límites de ellas (basándose en las teorizaciones de Marx), entendiéndolas como

[...] una unidad de producción mercantil y no [...] una unidad de producción mercantil capitalista a consecuencia de lo cual el campesino se propone la creación de valor, la maximización de la creación de valor y no la maximización de la valorización del capital ${ }^{20}$.

Como vemos, en los casos que tomamos como ejemplos de los estudios sobre el campesinado en la argentina, el término campesino aparece recortado, como menos globalizador de lo que significa en otras regiones de América Latina. Una tendencia marcada en buena parte de los estudios utilizados, es a relacionar campesinos con minifundistas y a ambos con pobreza rural. Por otro lado, aparece otra vertiente que remarca el carácter subordinado de las explotaciones campesinas en la Argentina. Comencemos por el primero de estos aspectos.

14. F. Delich (1972: 61).

15. P. Tsakoumagkos (1987: 230).

16. E. Archetti (1981b: 216).

17. R. Benencia (1987: 3).

18. N. Giarraca y S. Aparicio (1991).

19. N. D'Alessio (1969: 385).

20. N. D'Alessio (1969: 388). 
El campesino sería un minifundista carente de recursos, incapacitado de desarrollar una actividad que le permitiera subsistir adecuadamente, e incluso se le coarta la posibilidad de acumular. Si retomamos la definicion de Manzanal observaremos que los rasgos de los campesinos derivan de esas carencias estructurales. Sin embargo, en un trabajo anterior, la misma autora sobrepone a esas limitaciones estructurales una explicación basada en el tipo de estrategia racional adoptada:

Los minifundistas no son capitalistas, tienen una racionalidad diferente. No persiguen en su actividad la obtención de la máxima ganancia, sino el máximo ingreso, para poder hacer frente a sus necesidades más urgentes y las de su familia. Para esto su esfuerzo se concentra en lograr el mejor aprovechamiento de la mano de obra familiar, único bien disponible por otra parte ${ }^{21}$.

Este análisis abreva, en gran medida, en los trabajos realizados por el equipo del Servicio Nacional de Economía y Sociología Rural, de la Secretaría de Estado de Agricultura y Ganaderia ${ }^{22}$. En uno de éstos se afirma:

La racionalidad económica del minifundista es diferente a la del empresario, debido a su diferente dotación de recursos y forma social de la explotación. [...] su racionalidad èconómica tiene como objetivo asegurar la subsistencia familiar, para lo cual intenta maximizar un ingreso global que cubra dicha subsistencia aún cuando no se retribuyan todos los factores de la producción ${ }^{23}$.

Utilizando el método de confirmación por la negativa (al no cumplirse los preceptos que Max Weber indica como premisas que permiten maximizar la racionalidad del cálculo del capital, es que se está en presencia de algo distinto), concluyen en que se está frente a una racionalidad específica. Ésta es vista como manifiesta en la maximización del trabajo familiar con el fin de obtener la mayor masa de ingresos posibles, tanto en efectivo como en especies, en rela-

21. M. Manzanal y A. Rofman (1989: 67).

22. Si bien la labor de este grupo influyó notablemente en trabajos posteriores, otros estudios sostienen posturas similares para pequeños productores argentinos sin nutrirse, necesariamente, de aquellos trabajos; por ejemplo: «[...] la conducta campesina no está guiada por el móvil de la ganancia capitalista tal como ésta es concebida en el sector agrario capitalista" (N. D'Alessio, 1969: 403). Incluso, autores que no se refieren a la presencia campesina, sino a pequeños productores, utilizan el bagaje de aquel marginalismo-chayanoviano. Así, refiriéndose a los horticultores cercanos a la ciudad de Rosario (provincia de Santa Fe y segunda ciudad argentina en importancia económico-social), S. Cloquell y M. Trossero sostienen que en esas unidades, el sistema familiar sólo registra ingreso bruto, sumas destinadas a la renovación del capital, presupuesto personal y ahorros no invertidos en la explotación, concluyendo: «El productor de una unidad doméstica a medida que se incrementa la producción de su trabajo realizará un balance entre los factores económicos y una disminución en su cuota de trabajo. Si satisface la demanda de la familia con menos desgaste de trabajo, decrece la intensidad técnica de su trabajo como un todon (S. Cloquell; M. Trossero, 1992: 16).

23. M. Basco y otros (1981a: 13). 
ción con el número de consumidores. La influencia chayanoviana es notable, máxime cuando se enuncian las categorías económicas presentes en el tipo social minifundista: el ingreso total bruto, los costos en efectivo, lo que resta para la subsistencia familiar y el ingreso no monetario.

Frente a este planteo, aun cuando fue morigerado en un trabajo posterior escrito por un miembro del mismo equipo ${ }^{24}$, se aplica la crítica expresada para posturas similares por E. Maffei:

Con el desarrollo del capitalismo y la aparición de la frontera agrícola en el campo y, por lo tanto, de un mercado de tierra, es difícil poder sostener o aplicar hoy día las tesis centrales de Chayanov y pensar en la existencia de un modo de producción campesino o mucho menos de una clase campesina. Más utópico parece aún la idea de que hay una racionalidad opuesta a la maximización de los excedentes que se generan en la pequeña unidad productiva ${ }^{25}$.

Si bien no se plantea en los trabajos analizados la presencia de un «modo de producción campesino", llevando a última instancia la idea de una racionalidad diferenciada, éste puede ser enunciado. Pero lo importante de la cita anterior radica en que Maffei centra a la unidad campesina en el contexto capitalista, marco global en nuestro país. Llambí también planteó que en tanto se incrementen las relaciones entre las unidades campesinas y el sistema capitalista, se generan las condiciones objetivas que se manifiestan en un patrón de conducta y de valorización: una racionalidad común para ambos sectores ${ }^{26}$.

Por otro lado, si los campesinos/minifundistas no persiguen la tasa de ganancia, sino que sólo buscan maximizar su ingreso, estarían en condiciones de competir con el capitalismo, impidiendo la entrada de capital al agro, pues producirían para vender a un precio menor que el costo de producción capitalista ${ }^{27}$. Pero es más que evidente que el capitalista puede incurrir en grandes costos iniciales o fijos para poner en producción una unidad más eficiente, capaz de producir a un costo menor que el de los campesinos.

El tema de la racionalidad del campesino/minifundista fue central en muchas investigaciones, y sigue hasta hoy ocupando un lugar importante en los estudios sobre estos sujetos, tal como lo muestra un trabajo reciente sobre la mujer campesina del noroeste argentino ${ }^{28}$. Al mismo tiempo, se le asigna otro papel a esa figura del campesino/minifundista, es la de jugar el rol del sujeto central del panorama de la pobreza rural.

Manzanal y Rofman señalan que la pobreza rural es una realidad presente en la zona extrapampeana, la de las denominadas economías regionales, donde

24. P. Tsakoumagkos (1987).

25. E. Maffei (1979: 126).

26. L. Llambí (1981).

27. K. Vergopoulos (1980); C. Servolin (1977).

28. M. Basco y otros (coord.) (1992). 
cuantitativamente el campesinado ocupa un lugar importante, no menos que en lo cualitativo. Su importancia reside — afirman- en que son funcionales al sistema económico global al proveer de insumos a las agroindustrias a bajo costo, mano de obra barata a las grandes explotaciones, trabajadores no calificados al sector industrial y de servicios, etc. Esta explicación es ampliamente coincidente con el análisis de G. Gomes y A. Pérez sobre los objetivos que deben ser cumplidos por la agricultura "tradicional" en funcion del nuevo patrón de acumulacion ${ }^{29}$.

Esta postura, sostenida desde organismos internacionales como la FAO, encierra la presencia poderosa y articuladora del gran capital; indica una bipolarización entre un sector integrado a aquél, moderno, capitalista y pujante, y otro sector atrasado, tradicional y funcional al primero. De esta manera se presenta un panorama unilineal, ocultrando que dentro de los sectores campesinos hay un importante proceso de diferenciación social, como ya indicamos que señala Murmis. En el campo extrapampeano argentino, ese proceso - afectado recurrentemente por las crisis económicas - es una realidad no profundamente estudiada, pero sí mencionada en varios trabajos, como uno de mediados de la década de 1970 realizado por el mismo Murmis ${ }^{30}$. Otro eje de análisis es que la producción de alimentos a bajo costo es entendida por distintos autores latinoamericanos como una trasferencia de valor, de la cual se beneficiarían otros grupos: comerciantes, consumidores y empleadores de asalariados, que verían reducido el gasto alimentario de su salario. Como ya apuntó $\mathrm{O}$. Barsky, siguiendo a Marx, si los campesinos producen, dado su atraso tecnológico, invirtiendo una cantidad de horas de trabajo superior a la media (que es la medida del valor), eso no implica cesión de valor sino tiempo de trabajo socialmente no reconocido ${ }^{31}$.

Los trabajos que hacen hincapié en aquella relación de subordinación de la producción campesina, tanto los latinoamericanos en general como los argentinos en particular, se centran en la articulación de la unidad campesina de producción y con diferentes fracciones del capital, como el agroindustrial.

Para Tsakoumagkos y para Manzanal y Rofman los campesinos aparecen como eslabones en la cadena de producción y comercialización, sus funciones serían las de posibilitar espacios de valorización de capital y de amortiguar ciertas contradicciones del sistema como tal. El primero de los autores, tomando el caso de la producción de algodón, afirma que el componente campesino de la oferta del mismo permite abaratar el producto, y por ende, contribuye a la

29. Las unidades campesinas «[...] se orientan básicamente a: a) crear excedentes de mano de obra y liberalizar fuerza de trabajo para el clesarrollo de los segmentos capitalistas modernos agrícolas y, principalmente, no agrícolas; b) suministrar alimentos a bajo costo para el desarrollo de dichas actividades y segmentos, y c) suministrar a las economías centrales alimentos y materias primas a bajo coston (G. Gomes; A. Pérez, 1983: 141).

30. M. Murmis (s/f).

31. O. Barsky (1990: 48); C. Marx (1986: tomo I, cap. V). 
valorización del capital agroindustrial ${ }^{32}$. En buena medida, esa baratura provendría de la autoexplotación campesina, no remunerando al factor trabajo. Como sostiene Lehmann, la baratura de los productos campesinos derivan de que sus costos se calculan de manera distinta a la producción capitalista, y principalmente a que la empresa campesina puede absorver más explotación que la basada en el trabajo asalariado ${ }^{33}$. Aquí, al igual que en la explicación de Tsakoumagkos, se halla implícita la noción chayanoviana de la existencia de un equilibrio interna en la unidad de producción campesina que le permite sobrevivir en condiciones adversas ${ }^{34}$.

Pero lo esencial en el aspecto tratado, es que ese producir más barato no es una relación causal con el precio de producción, entendida como originaria de su descenso. Si permite esta situación acumular excedentes - como sostiene O. Barsky - dado que el precio depende, entre otros factores, de la relación global de la oferta y la demanda del producto y del carácter del proceso de comercialización ${ }^{35}$.

Otros autores refuerzan la idea de la subordinación campesina frente a la agroindustria, en tanto que ésta los somete a un intercambio desigual. Si bien la desigualdad siempre se halla presente en la relación entre dos magnitudes distintas de producción, se agudiza cuando se trata de pequeños productores y de un complejo agroindustrial ${ }^{36}$.

Analizando esta relación en el caso argentino, Tsakoumagkos estudia la relación entablada entre los productores avícolas de la provincia de Entre Ríos y las agroindustrias del sector. Su conclusión es que esa relación alcanza tal grado de subordinación de los primeros a las segundas, que terminan por «vaciar» de contenido campesino a esos productores (implicando que el autor consideraba a los mismos como tales) $)^{37}$.

Como indica Durston, la integración subordinada se realiza a través de una empresa semimonopólica que domina el proceso productivo comercial en prácticamente todos sus aspectos, pero sin embargo no se adueña de los medios de producción del campesino. En última instancia, esos productores se transformarían en semiproletarios, enlazando el "vaciamiento" del que habla Tsakou-

32. P. Tsakoumagkos (1987: 237).

33. D. Legmann (1980: 18-19).

34. «Frecuentemente, el equilibrio básico interno de la unidad familiar de explotación agrícola hace que sean aceptables remuneraciones muy bajas por unidad doméstica de trabajo, lo cual le pẹrmite existir en condiciones que llevarían a la ruina segura a una unidad de explotación capitalistan (A. Chayanov, 1985: 94).

35. O. Barxky (1990: 51).

36. Así, J. Durston afirma que: «El mecanismo de extracción basado en los términos de intercambio en lo esencial no se alteró con la modernización, sino que aumentó al introducir un nuevo elemento: la creciente utilización de créditos y de insumos tecnológico-intensivos por parte de los productores campesinos" (1982: 168).

37. "Los avicultores totalmente integrados conservan la forma campesina pero ninguno de sus contenidos. Ya no son campesinos pero tampoco son formalmente asalariados" (P. Tsakoumagkos, 1987: 247). 
magkos con la visión tremendista/escatológica de Ernest Feder, respecto al futuro del campesinado latinoamericano ${ }^{38}$.

M. Manzanal también observa la relación asimétrica entre el campesinado y la producción capitalista. Sostiene que muchas producciones extrapampeanas se basan en que el minifundista venda su fuerza de trabajo transitoriamente, se semiproletarice, pero sin abandonar su parcela, dado que el mantenerla en producción es una forma de abaratar el pago de la fuerza de trabajo en las explotaciones capitalistas ${ }^{39}$. En Manzanal, la semiasalarización no convierte en semiasalariado a quien la sufra, sino que reafirma su forma campesina. Tsakoumagkos refuerza esta idea al sostener que en la estructura campesina argentina hay cierto predominio de los semiasalariados ${ }^{40}$. Aún más, C. Flood en una primera aproximación a una tipología de campesinos, con especial referencia al caso argentino, incluye entre aquéllos una "forma impura de campesinado", los semiasalariados. Este tipo combinaría la explotación de un predio reducido con la subocupación del potencial de trabajo familiar en esa explotación y la canalización de este "resto" al mercado de trabajo local ${ }^{41}$.

Frente a análisis como los anteriores se puede esgrimir que la presencia de trabajo asalariado entre estos pequeños productores es un signo de que su "condición campesina" no se refuerza, sino justamente lo contrario. La venta de fuerza de trabajo fuera del predio estaría reflejando un elevado grado de subsunción al capital, aun mayor que si se realizara directamente su producto ${ }^{42}$.

Aquellos autores que sostienen que en los últimos años se produjo un proceso de «recampesinización» en la Argentina, cuando antiguas parcelas de residencia se transforman en producciones de subsistencia ${ }^{43}$, pueden ser contradichos con la misma línea analítica. En efecto, si en esa parcela lo que se produce es para el autoconsumo, el producto se convierte en parte del salario, beneficiando así al capital ${ }^{44}$.

En los estudios mencionados está implícita la presencia de campesinos en nuestro país. Pero como sostuvimos más arriba, creemos más operativa la uti-

38. E. Feder (1976 y 1984). Cabe aclarar que Tsakoumagkos remarca que éste no es necesariamente el destino de todos los campesinos, sino que el mismo depende del desarrollo de la rama agroindustrial a la que se encuentren articulados.

39. "[...] la semiasalarización es una forma de obtención de ingresos muy frecuente entre el campesinado argentino y ha consolidado su presencia a lo largo de los años, sin implicar la transformación del campesino en asalariado y, por lo tanto, en muchos casos ha contribuido a mantener la forma campesina” (M. Manzanal, 1990: 302).

40. P. Tsakoumagkos (1987:238).

41. C. Flood y A. Tobin (1978: 67).

42. Analizando el caso mexicano, G. Foladori dice: «No puede argumentarse, bajo ningún criterio, que la venta de su fuerza de trabajo es el elemento que refuerza su calidad de campesino. Es más bien el elemento que refuerza la calidad de proletarion (1981: 107).

43. S. Aparicio, N. Giarraca y M. Teubal (1992: 136).

44. "Es ridículo pensar que, en una sociedad gobernada por la ley del valor, donde la producción de mercancías se amplía y se extiende permanentemente, la producción directa de un proletario agrícola constituye el polo que permita definirlo como campesinon (G. Foladori, 1981: 108). 
lización del concepto de pequeños productores. Tomando como una de sus delimitantes la venta de una parte significativa de la fuerza de trabajo familiar ${ }^{45}$, los semiasalariados quedarían fuera del espectro de análisis. Sin embargo, esto no implica que dentro de las estrategias productivas de las unidades de pequeños productores no se incluya la venta temporal de parte de la fuerza de trabajo familiar. Esta temática nos remite nuevamente a la de la racionalidad de estos productores.

Recordemos que numerosos trabajos les asignan una racionalidad diferenciada, no capitalista, que no busca la ganancia, sino que los campesinos se limitan a maximizar el ingreso, persiguiendo la reproducción simple de su unidad ${ }^{46}$.

Esta racionalidad impediría, según los sostenedores de este análisis, superar el umbral de la acumulación; de ahí la relación que se establece entre campesinos y pobreza rural. Si aceptar esta idea de una racionalidad diferencial es complejo, aún en sociedades de larga tradición de comunidades campesinas (como en la región andina), cuánto más lo es para Argentina, donde el desarrollo capitalista es temprano. Uno de los autores que seguimos, P. Tsakoumagkos, si bien acepta aquella idea, la matiza frente a la realidad del país. Sostiene que la lógica campesina no resulta suficiente si no se la entiende desde el contexto de una economía global, dependiente y de bajo nivel de absorción de población en empleos productivos. Esto parece mucho más sensato que afirmar que la racionalidad campesina/minifundista se asocia a la herencia cultural transmitida por generaciones desde antes de la colonia, en cuanto a prácticas productivas y de intercambio, como lo hacen Manzanal y Rofman ${ }^{47}$. Sostener esto en forma generalizada, equivale a afirmar que sobre el territorio nacional se desarrollaron civilizaciones que desplegaron algún modo de producción que implicara la presencia de la tradicional unidad campesina, sea el feudal o el asiático. Ahora, ¿el chaco, el litoral, los valles neuquinos lo fueron? ¿Qué tradición campesina pudieron legar mapuches, tobas o matacos?

Relacionado con la posición de Tsakoumagkos aparece Durston afirmando que las estrategias económicas campesinas derivan en forma directa de su situación de clase sociat $t^{8}$. Estudiando el caso ecuatoriano, $\mathrm{O}$. Barsky enmarca las estrategias campesinas en la sociedad global. Afirma que hay una serie de determinantes de los procesos de cambio que no se entienden desde la propia unidad, sino que la unidad es un organismo que va adecuando y ensayando

45. M. Piñeiro e I. Llovet (1986a: 28).

46. Desde organismos internacionales se postula lo anterior en los siguientes términos: «La producción en las unidades agrícolas campesinas tiene por objeto la reproducción de la unidad y no la maximización de la tasa de ganancia capitalista. Esto significa que la ley fundamental de movimiento de la economía campesina es garantizar la reproducción de las familias vinculadas a sus unidades al nivel más alto posible (maximización del ingreso familiar indivisible). Por consiguiente quedan excluidas de esta definición de la economía campesina todas aquellas unidades de producción cuyo objetivo fundamental es maximizar su tasa de ganancian (R. Brignol; J. Crispi, 1982: 144).

47. P. Tsakoumagkos (1987: 245); M. Manzanal y A. Rofman (1989: 68).

48. J. Durston (1982: 161). 
respuestas de diverso corte a procesos de cambio cuya lógica es más regional o nacional, pero por lo menos tiene una lógica en un espacio social más amplio ${ }^{49}$.

En efecto, los agentes sociales toman sus decisiones respondiendo no sólo a las señales de la "mano invisible» del mercado (las instituciones mercantiles), sino que inciden tambien factores extraeconómicos (las instituciones no mercantiles). Como sostiene Llambi, la racionalidad de los actores sociales es siempre contingente, por lo cual, si se problematiza, se resolverá por la investigación empirica y no por la teorización abstracta ${ }^{50}$.

Hay un número considerable de estudios, a nivel latinoamericano, que enfatizan este aspecto, llegando a conclusiones opuestas respecto a los postulados chayanovianos. Por ejemplo, los trabajos sobre la acumulación campesina en Ecuador muestran que en condiciones adecuadas, los productores campesinos logran superar el umbral mencionado e iniciar un proceso de reproducción ampliada ${ }^{51}$. En contrapartida, para el caso de los pequeños productores argentinos, entendiéndolos o no como campesinos, las investigaciones empíricas parten del paradigma de la imposibilidad de acumulación por parte de los mismos, enfatizando que esto proviene de la lógica interna de esas unidades. Sólo algunos trabajos aislados, con estudio empírico, dejan entrever que entre los minifundistas las posibilidades de acumulación no son descartables per se $e^{52}$. Pero, insistimos, la opinión predominante es la de asignarle una racionalidad diferenciada. Esto implica olvidar, ocultar o desconocer que estos productores combinan ciclos agrícolas y pecuarios, la producción propia o en aparcería, el distribuir la producción a lo largo del ciclo en diferentes lotes, con el objetivo de disminuir el riesgo climático, la producción de subsistencia y para el mercado ${ }^{53}$. En otras palabras, estos pequeños productores que los autores tratados llaman campesinos o minifundistas, no tienen una racionalidad económica distinta de la del pequeño burgués o del farmer ${ }^{54}$.

La especificidad planteada ex-post por esos autores se debe, en lo fundamental, a las restricciones determinadas desde lo social que enfrentan esos actores, y a la precariedad de su reproducción económica, y aún física. Y, por otro lado, al mismo tiempo entrelazado con el uso "amplio" del término campesino, ¡se puede, seriamente, llamar campesinos y asignarles una racionalidad dife-

49. O. Barsky (1984a: 122-123).

50. L. Llambi (1990: 225).

51. O. Barsky (1984 b); O. Barsky e I. Llovet (1986).

52. Algunos de estos trabajos fueron reunidos en una compilación efectuada por $\mathrm{O}$. Barsky, que aún se mantiene inédita; entre los que abordan de lleno nuestra cuestión, se menciona una investigación de G. Neiman sobre los pequeños productores de Formosa.

53. "Todo ello implica una racionalidad signada por una clara atención a las seńales del mercado y, al mismo tiempo, una adecuación sutil de las estrategias familiares para transformar estas señales en la mayor captura posible de excedentes" (O. Barsky, 1990:49).

54. «No hay nada, por tanto, misteriosamente —ontológicamente, si se quiere - distinto entre el cálculo del campesino y el del farmer. Son sólo producto de distintas condiciones de mercados, acumulación, etc.» (J. Caballero, 1984: 10). 
renciada a los chacareros/farmers de la pampa húmeda o a los colonos del noreste? ¿ $\mathrm{O}$ es que la presencia de la mano de obra familiar - rasgo campesino paradigmático para muchos de nuestros autores- tiene tal peso que articula, absolutamente, en sí a todos los otros factores que intervienen en la lógica de la unidad?55.

A título de ejemplo, repasemos otro trabajo sobre el agro argentino y que se inscribe en la línea de la racionalidad diferenciada. $H$. Vessuri, estudiando una zona tucumana, caracteriza a la economía campesina como mercantil, constituyendo las mercancías el principio y el fin de las transacciones. En ese vender y comprar no hay lugar para la búsqueda de la ganancia o de la acumulación, sólo para la satisfacción de las necèsidades ${ }^{56}$.

Sin eludir que su universo de análisis sufre cambios de diferenciación, Vessuri sostiene que los mismos vienen impuestos desde fuera, por fuerzas externas a la economía campesina; implícitamente, entonces, la producción campesina no es capaz por sí sola de variar. En realidad, como marcó W. Thiesenhusen, el "capullo del hábito" que, según algunos antropólogos, envolvía a los campesinos, casi siempre ha resultado ser notablemente débil ${ }^{57}$.

La experiencia en América Latina es profusa en antecedentes de inversión, por parte de estos pequeńos productores, de su fuerza de trabajo en actividades que conducen a posibilitar la agricultura o a intensificarla. En los casos de comunidades, es corriente el trabajo colectivo en obras de drenaje, de protección contra crecientes de los cursos hídricos, la construcción de infraestructuras de regadío, etc.; en el espacio individual de producción, es común encontrar inversiones importantes en montar cultivos permanentes, tal los casos del café, el cacao y la viña. Ante esto, y refiriéndose a América Latina en general, pero aplicable a nuestro país, E. Ortega dice:

Se sugiere por tanto revisar la hipótesis que sostiene que la agricultura campesina no tiene capacidad de acumulación; lo que ocurre es que la naturaleza de la intervención es distinta. [...] Su inversión se basa en el conocimiento del medio y apela fundamentalmente a un recurso abundante como es la mano de obra [...]. Infortunadamente se carece de todo tipo de dato cuantitativo que permita ilustrar el significado de este tipo particular de inversión que realiza el campesino ${ }^{58}$.

De manera similar es necesario obrar respecto a la tendencia a considerar a estos productores como reticentes al cambio, en especial al tecnológico. El clásico estudio de $\mathrm{E}$. Rogers sostiene que uno de los rasgos de los campesinos es su no aceptación del cambio, de las ideas nuevas en general, estando esto ori-

55. Véanse los distintos trabajos de E. Archetti.

56. «El vender para comprar implica que su participación en el mercado como vendedor de mercancías es sólo un medio para realizar un propósito no conectado con la circulación de mercanćas, a saber, la satisfacción de necesidades - las de su grupo doméstico- que están definidas culturalmente) (H. Vessuri, s/f: 39 ).

57. W. Thiesenhusen (1979: 224).

58. E. Ortega (1982: 108-109). 
ginado - y reforzado - en la herencia cultural que reciben ${ }^{59}$. En cambio, otros autores afirman que si la nueva tecnología - aún la más sencilla - no es adoptada rápidamente por los pequeños productores, las causas son otras. Por ejemplo, en el caso de las tecnologías mecánicas la inadecuabilidad de la escala de uso óptimo frente a la escala de superficie controlada por aquéllos.

[...] nos queda poca duda respecto a que la extrema parcelación de la tierra es efectivamente un freno al cambio técnico, pero no por una supuesta «aversion» de los campesinos al cambio, sino porque existe una inadecuación entre la oferta de técnicas mayormente indivisibles y la estructura de la propiedad muy parcelada ${ }^{60}$.

La cita anterior, correspondiente a un estudio de caso efectuado en la sierra peruana, es ampliamente generalizable para destacar que, en buena parte, la «lenta modernización» de los pequeños productores tiene como causales a factores externos a éstos. Incluso, el mismo estudio afirma que en un primer análisis, la hipótesis ampliamente difundida de la adversión al riesgo de estos productores, no se vería correspondida en situaciones dadas (requiriéndose, para corroborar esto, investigaciones específicas). Y más aún, cuando ciertos productos tienen una elasticidad de precio elevada, es más factible que los pequeńos productores adopten tecnologías que influyan sobre su obtención ${ }^{61}$. Esto mismo es analizable en el caso argentino, donde se estudia un proyecto de desarrollo rural impulsado por una organización no gubernamental (FUNDAPAZ) entre pequeños productores cabriteros de la provincia de Santiago del Estero.

$\mathrm{La}$ actividad ganadera caprina se combina con la transformación de la leche obtenida, produciendo quesos. De ser dos zonas (Robles y Garza, ambas en dicha provincia) de características estructurales de profunda pobreza, se pasó a organizar a los productores, entrenándolos en técnicas de manejos de los rebaños, en los cuidados de la leche ordeñada, en la construcción de mejoras. El primer paso, y que es lo que a nosotros nos ocupa aquí, comenzó con la difusión del llamado "botiquín veterinario comunitario", destinado a disminuir la mortandad del stock de animales. Éste fue rápidamente aceptado por los productores, contradiciendo aquello de la resistencia al cambio y a la adopción de innovaciones.

Para finalizar este aspecto, nos parece importante rescatar el análisis que realiza C. Flood acerca de la racionalidad del campesinado (recordemos que este autor escribe en términos genéricos pero con mención especial al caso de lo que él llama "campesinos argentinos»). Si bien acepta algunos de los postulados tradicionales de Wolf respecto al manejo de la unidad por parte de los

59. E. Rogers y L. Svenning (1973).

60. E. Gonzales de Olarte (1987: 163).

61. Uno de los técnicos que trabajó en ese proyecto sostiene: «[...] esto demuestra que cuando el diagnóstico del problema está bien hecho, es mentira que el pequeño productor sea resistente a la innovación tecnológicas (citado en J. Iglesias, 1990: 29; cfr. M. Posada, 1992). 
campesinos, Flood considera que las diferencias entre el empresario y el campesino no son tan profundas, derivando aquéllas, en gran medida, de la dispar magnitud y estabilidad de los recursos de que disponen, originando que en caso de una caída de la tasa de ganancia el empresario pueda cambiar de ramo de actividad, mientras que el campesino no tiene siquiera la posibilidad de acceder a tal ganancia. Todos los productores, aún el más pequeño, realizan un balance anticipado de sus recursos y sus necesidades, y se aferrarán a la producción de un rubro que les asegure una combinación óptima de recursos disponibles ${ }^{62}$.

\section{IV}

En síntesis, los estudios agrarios efectuados sobre el heterogéneo espectro de los llamados pequeños productores presentan como una de sus características principales la de asignarles a los mismos rasgos campesinos. No sólo utilizando esa expresión de manera genérica, descriptiva, como proponía Archetti, sino con gran parte de su carga teórica. Así, aparece la noción de una racionalidad diferenciada, no maximizadora de ganancia sino del ingreso, lo cual se entrelaza con la idea de resistencia a los cambios y de búsqueda de minimizar riesgos.

El extrapolar ciertos análisis microeconómicos - de matriz chayanovianapara efectuar explicaciones con implicancias de nivel macro, termina por desvirtuar la realidad social imperante en el agro. El entender a todo productor con mano de obra familiar y con escasa dotación cuantitativa de recursos de tierra y capital, como un campesino, englobando incluso aquí a semiasalariados y a proletarios rurales, no hace más que ocultar los procesos de diferenciación social imperantes en el agro, como las dificultades propias de cada grupo. Como afirma N. Giarraca, en referencia a la aplicación de políticas, y que nosotros podemos extender a otros campos:

Con la conceptualización generalizada de minifundista o campesino, aun con buenas intenciones, se puede llegar a velat estas heterogeneidades y diferencias que es necesario sacar a la luz y respetar en las formulaciones de políticas opcionales ${ }^{63}$.

62. De manera similar se puede analizar su adopción o no de ciertas tecnologías, concluye Flood: «El apego a técnicas de cultivo (y modos de comercialización) ya conocidas no sólo constituye un comportamiento erigido sobre el principio de la seguridad a corto plazo, sino que tiene que ver con la evaluación de recursos disponibles. No puede atribuirse a ignorancia o indolencia, a fatalismo o temor al riesgon (C. Flood, 1978: 49).

63. N. Giarraca (1990: 64). Un caso particular de confusión de la realidad agraria argentina, y por ende, de erróneos diagnósticos - con su consecuencia de propuestas divorciadas de la sociedad- son los distintos trabajos que analizan al campo argentino efectuados por autores ligados al aparato partidario del comunismo argentino. Intentando conciliar el análisis de Lenin sobre la Rusia prerrevolucionaria y el agro pampeano y extrapampeano, se esforzaron por reconocer a campesinos ricos, medio ricos y pobres, a semiproletarios y a terratenientes; y más aún, asignan a una corporación representativa de una fracción de la burguesía agraria, como es la Federación Agraria, una base campesina. Cfr. J. García (1964, 1972 y 1987); R. San Esteban (1975 y 1979); C. Mendoza (coord.) (1985). 
Marcelo Germán Posada

\section{Bibliografía}

Aparicio, Susana; Giarraca, N.; Teubal, M. (1992). "Las transformaciones en la agricultura; el impacto sobre los sectores sociales". En JORRAT, J.; SAUTU, R. (comp.). Después de Germani. Exploraciones sobre estructura social de la Argentina. Buenos Aires: Paidós, p. 123-141.

ARCHETTI, Eduardo (1981a). «Una visión general de los estudios sobre el campesinado». En ARCHETII, E. Campesinado y estructuras agrarias en América Latina. Quito (Ecuador): CEPLAES, p. 13-48.

- (1981b). «El proceso de capitalización de campesinos argentinos». En ARCHETTI, E. Campesinado y estructuras agrarias en América Latina. Quito (Ecuador): CEPLAES, p. 203-222.

BARSKY, O.; LloveT, I. (1986). "Pequeña producción y acumulación de capital: los productores de papa de Carchi, Ecuador". En PiñeIRO, M.; LLOveT, I. Transición tecnológica y diferenciación social. San José (Costa Rica): IICA, p. 251-326.

BARSKY, Osvaldo (1984a). "Comentario". En Field, L.; ChIRIBOGA, M. Agricultura andina: propuesta de investigación. Quito (Ecuador): CAAP.

-_(1984b). Acumulación campesina en el Ecuador. Quito (Ecuador): FLACSO.

-(1990). Políticas agrarias en América Latina. Buenos Aires: Imago Mundi.

BASCO, Mercedes y otros (1981a). Esquema conceptual y metodología para el estudio de tipos de establecimientos agropecuarios con énfasis en el minifundio. Buenos Aires: SEAG.

- y otros (1981b). Evolución del minifundio en la Argentina. 1960-1980. Buenos Aires: SEAG.

- y otros (coord.) (1992). Trabajando con mujeres campesinas en el noroeste argentino. Buenos Aires: IICA.

BASCO, Mercedes (1993). Hacia una estrategia de desarrollo rural para la Argentina. Buenos Aires: IICA.

BENENCIA, Roberto (1987). Liderazgo y organización campesina. Nacimiento, evolución y crisis de una cooperativa de productores correntinos de tabaco. Buenos Aires: CEIL. (Reeditado por GADIS en 1992.)

BRIGNOL, Raúl; CRISPI, J. (1982). «El campesinado en América Latina. Una aproximación teórica». Revista de la CEPAL, n. 16, Santiago de Chile, abril, p. 143-154.

CABALLERO José (1984). Campesinos y farmers: desarrollo capitalista y tipo de empresa agraria. Roma (Italia): FAO, mimeo.

CEPAL (1982). Economía campesina y agricultura empresarial. México: Siglo XXI.

CHAYANOV, Alexander (1985). La organización de la unidad económica campesina. Buenos Aires: Nueva Visión, 1985.

Cloquell, S.; Trossero, M. (1992). «Diagnóstico de la estructura productiva del área hortícola de Rosarion. En BARSKY, O. y otros. Explotaciones familiares en el agro pampeano. Buenos Aires: CEAL, vol 3, p. 7-129.

CONSEjo FEDERAL DE INVERSIONES (1975). Diagnóstico de la estructura social de la region del noreste argentino. Buenos Aires: CFI.

CRISTIÄ, Carlos (1974). «En torno a la estructura de clases en el campo: reflexiones exploratorias sobre el concepto de campesinadom. Seminario sobre las explotaciones agricolas familiares en Argentina. Horco Molle: UNT.

DELICH, Francisco (1972). «Estructura agraria y tipos de organización y acción campesina». En MARSAL, J. (comp.). Argentina conflictiva. Buenos Aires: Paidos, p. 5885. 
DURSTON, John (1982). "Clase y cultura en la transformación del campesinado". Revista de la CEPAL, n. 16, Santiago de Chile, abril, p. 155-177.

FEDER, Ernest (1976). "La nueva penetración de la agricultura de los países subdesarrollados por los países industrializados y sus empresas multinacionales". El Trimestre Económico, n. 169, México.

-(1984). Violencia y despojo del campesino: latifundismo y explotación. México: Siglo XXI.

FLOOD, Carlos; Tobin, A. (1978). La escuela rural productiva. Buenos Aires: CIE, Cuaderno n. 26.

FOLADORI, Guillermo (1981). Polémicas en torno a las teorias del campesinado. Mexico: ENAH-INAH, Cuicuilco.

García, José (1964). "Argentina». En Pushev, G.; Kulagain, N. (comp.). La cuestión agraria y el movimiento de liberación nacional. Buenos Aires: Fundamentos, p. $350-339$.

-(1972). El campo argentino a 60 años del Grito de Alcorta. Buenos Aires: Centro de Estudios.

-(1987). Reforma agraria y liberación nacional. Buenos Aires: CEAL.

GIARRACA, Norma (1990). «El campesinado en la Argentina: un debate tardío». Realidad Económica, n. 94, Buenos Aires, 3er bimestre, p. 54-65.

GIARRACA, Norma; APARICIO, S. (1991). Los campésinos cañeros: multiocupación y organización. Buenos Aires: UBA-Facultad de Ciencias Sociales.

GOMES, G.; PEREZ, A. (1985). "El proceso de modernización de la agricultura latinoamericana: características y breve interpretación». En M. PIÑEIRO, M.; TRIGO, E. (ed.). Cambio técnico en el agro latinoamericano. San José (Costa Rica): IICA . GOMEZ, Sergio (1980). Descomposición campesina: análisis de los signatarios de la reforma agraria. Santiago de Chile: PREALC/OIT.

GONZALES DE OLARTE, Efraín (1987). La lenta modernización de la economia campesina. Lima (Perú): IEP.

HEYNIG, Klaus (1982). "Principales enfoques sobre la economía campesina». Revista de la CEPAL, n. 16, Santiago de Chile, abril, p. 115-142.

IGLESIAS, Jorge (1990). «Las cabras y los cambios». Dinámica Rural, n. 258, abril.

LEHMANNN, David (1980). "Ni Chayanov ni Lenin: apuntes sobre la teoría de la economía campesina». Estudios Rurales Latinoamericanos, vol. 3, n. 1, enero-abril, p. 5-23.

-(1980). «Proletarización campesina: de las teorías de ayer a las prácticas de mañana». Nueva Antropología, año IV, n. 13-14, México.

LENIN, Vladimir (1978). Teoría de la cuestión agraria. México: Cultura Popular.

LLAMBÍ, Luis (1981). "Las unidades de producción campesina en el sistema capitalista: un intento de teorización». Estudios Rurales Latinoamericanos, vol. 4, n. 2, mayoagosto, p. 125-153.

-(1990). "La economía política del campesinado: apuntes para una nueva agenda teórica y de investigación". Estudios Rurales Latinoamericanos, vol. 13, n. 3, Bogotá (Colombia), septiembre-diciembre, p. 209-241.

MAFFEI, Eugenio (1979). "Algunas consideraciones sobre el campesinado minifundista latinoamericano. La agricultura de subsistencia y el concepto de economía campesina". Estudios Rurales Latinoamericanos, vol. 2, n. 1, Bogotá (Colombia), p. $122-128$.

ManZANAL, Mabel (1988). "El minifundio en la Argentina: políticas alternativas para una realidad poco conocida». XX Congreso Internacional de Economistas Agrarios. La economía agraria argentina. Buenos Aires: AAEA, p. 143-164. 
-(1988). La situación ocupacional de los productores minifundistas en la Argentina. Buenos Aires. Proyecto Gobierno Argentino-PNUD-OIT, documento de trabajo n. 30.

- (1990). «El campesinado en la Argentina. Reflexiones para la formulación de políticas". Estudios Rurales Latinoamericanos, vol. 13, n. 3, Bogotá (Colombia), septiembre-diciembre, p. 299-315.

- (1993). Estrategias de sobrevivencia de los pobres rurales.

Manzanal, Mabel; Rofman, A. (1989). Las economías regionales de la Argentina. Crisis y politicas de desarrollo. Buenos Aires: CEAL.

MarX, Karl (1986). El capital. Crítica de la economía politica. Mexico: FCE, 3 vols. MendoZA, Carlos (coord.) (1985). La cuestión agraria en la Argentina. Buenos Aires: Anteo.

MURMIS, Miguel (1992). «Tipología de pequeños productores campesinos en América». En PEON, César (comp.). Sociologia rural latinoamericana. Hacendados y campesinos. Buenos Aires: CEAL, p. 79-117.

- (s/f). «Sobre una forma de apropiación y utilización del espacio rural: el terrateniente-capitalista pampeano y un intento de transformarlon. En MURMIS, M.; BENGOA, J.; BARSKY, O. Terratenientes y desarrollo capitalista en el agro. Quito (Ecuador): CEPLAES, p. 11-58.

OrTEGA, Emiliano (1982). «La agricultura campesina en América Latina. Situaciones y tendencias". Revista de la CEPAL, n. 16, Santiago de Chile, abril, p. 77-114.

PINNEIRO, Martín; LLOVET, I. (1986a). «El campesinado como problema de investigación». En PIÑEIRO, M.; LLOVET, I. (ed.). Transición tecnologica y diferenciación social. San José (Costa Rica): IICA, p. 9-38.

PiñeIRO, Martín; LLOVE'T, I. (1986b). «Estado, cambio técnico y pequeños productores». En PiÑEIRO, M.; LloVET, I. (ed.). Transición tecnológica y diferenciación social. San José (Costa Rica): IICA, p. 329-350.

Orlando Plaza, J. (ed.) (1979). Economía campesina. Lima: Desco.

POSADA, Marcelo (1992). "Crisis estatal y nuevo entramado social: la emergencia de las organizaciones no gubernamentales. $\mathrm{El}$ ro1 de las ONGs en el agro argentino". Revista Paraguaya de Sociología, año 28, n. 85, Asunción (Paraguay), septiembrediciembre, p. 89-131.

POSADA, Marcelo (comp.) (1993). Sociología rural argentina. Buenos Aires: CEAL.

ROGERS, E.; SVENNING, L. (1973). La modernización entre los campesinos. México: F.C.E.

THIESENHUSEN, William (1979). «Los años ochenta: ¿década del campesino?». Estudios Rurales Latinoamericanos, vol. 2, n. 2, mayo-agosto, p. 224-234.

TSAKOUMAGKOS, Pedro (1987). «Sobre el campesinado en Argentina». Revista Argentina de Economia Agraria, vol. I, tomo II, Buenos Aires, p. 229-269.

VERGOPOULUS, Kostas (1980). «El papel de la agricultura familiar en el capitalismo contemporáneo". Cuadernos Agrarios, n. 9, México.

VESSURI, Hebe (s/f). La estructura socioeconómica local-La Ramada de Abajo/La Virginia: campesinos y empresarios capitalistas. Buenos Aires: CICSO. Serie reimpresiones, $\mathrm{n}$. 2, p. 38-56.

WOLF, Eric (1970). Los campesinos. Barcelona (España): Labor. 